\title{
Observations of bentonite erosion from solar-driven moisture migration in GCLs covered only by a black geomembrane
}

\author{
W. A. Take ${ }^{1}$, R. W. I. Brachman ${ }^{2}$ and R. K. Rowe ${ }^{3}$ \\ ${ }^{1}$ Associate Professor \& Canada Research Chair in Geotechnical Engineering, GeoEngineering Centre \\ at Queen's - RMC, Queen's University, Kingston, Canada, K7L 3N6, Telephone: +1 6135333124 , \\ Telefax: +16135332128,E-mail: andy.take@civil.queensu.ca \\ ${ }^{2}$ Professor, GeoEngineering Centre at Queen's - RMC, Queen's University, Kingston, Canada, K7L 3N6, \\ Telephone: +1613533 3096,Telefax: +16135332128,E-mail: brachman@civil.queensu.ca \\ ${ }^{3}$ Professor and Canada Research Chair in Geotechnical and Geoenvironmental Engineering and Killam \\ Fellow, GeoEngineering Centre at Queen's - RMC, Queen's University, Kingston, Canada, K7L 3N6, \\ Telephone: +1613533 3113, Telefax: +16135332128,E-mail: kerry@civil.queensu.ca
}

Received 30 December 2013, revised 4 July 2014, accepted 5 July 2014

\begin{abstract}
Manufacturers of geosynthetic liner materials recommend that composite geomembrane/geosynthetic clay liners (GCLs) be covered in a timely fashion to avoid potential issues that may arise under the action of long-term solar exposure. In this paper, field evidence of a new, never before reported solar-exposure driven damage mechanism for GCLs covered only by a black geomembrane and left exposed for more than 3 years is presented. Solar exposure can give rise to a large daily variation in geomembrane temperature, which causes a moisture cycle within the interface between the geomembrane and GCL resulting in the formation and flow of condensed moisture beneath the geomembrane. All four of the GCL products investigated at the Queen's University Environmental Liner Test Site were shown to have experienced significant bentonite erosion after 4.7 years of exposure. Erosion was identified in the field through a tactile survey of GCL panels in which the stiffness response of the GCL to touch was used to identify eroded zones. A change in the colour of the GCL, although useful to identify possibly eroded zones in some GCL products, proved ineffective in others. Erosion features were observed with widths up to and exceeding $200 \mathrm{~mm}$ across, making them unlikely to undergo self-healing upon hydration and application of normal stress. As a result, the observed erosion features would have severe adverse consequences for leakage rates through the GCL component of a composite liner barrier system. These observations provide yet another strong motivation for timely covering of composite landfill liner systems.
\end{abstract}

KEYWORDS: Geosynthetics, Geosynthetic clay liners, Barrier systems, Bentonite, Erosion

REFERENCE: Take, W. A., Brachman, R. W. I. and Rowe, R. K. (2015). Observations of bentonite erosion from solar-driven moisture migration in GCLs covered only by a black geomembrane. Geosynthetics International, 22, No. 1, 78-92. [http://dx.doi.org/10.1680/gein.14.00033]

\section{INTRODUCTION}

Geosynthetic clay liners (GCLs) are often used in combination with a geomembrane (GMB) as a composite liner system which has been shown to provide a highly effective barrier to advective transport (Bonaparte et al. 2002; Rowe et al. 2004; Rowe 2012). Much recent research has been conducted concerning the performance of GCLs either alone or as part of composite liner systems (Take et al. 2009, 2012; Benson et al. 2010a, 2010b; Dickinson and Brachman 2010; Gates and Bouazza 2010; Hornsey et al. 2010; Lange et al. 2010; Rosin-Paumier et al. 2010;
Shackelford et al. 2010; Azad et al. 2011, 2012; Kang and Shackelford 2011; Rowe and Verge 2013). It is known that there is a need to assess the potential movement of bentonite within the GCL from local extrusion at stress concentrations such as wrinkles or gravel particles (Koerner and Narejo 1995; Fox et al. 2000; Stark et al. 2004; Dickinson and Brachman 2006, 2008) or, out of the GCL from internal erosion under a hydraulic gradient normal to the plane of the GCL (Rowe and Orsini 2003; Dickinson and Brachman 2010). However, there has been relatively little literature dealing with the field performance of GCLs 
as part of exposed composite liners - in part, because GCLs should not be left exposed for prolonged periods of time - and none dealing with the issue to be addressed in this paper.

In order to attain the potentially very low leakage rates with a composite GMB/GCL liner, it appears to be very important to follow GCL manufacturer recommendations during construction to promptly cover the liner with sufficient ballast (e.g. gravel) such that the GCL does not experience excessive wet/dry cycles from solar exposure. Manufacturers of geosynthetic barrier products hence recommend that geomembrane /GCL composite landfill liners be covered in a timely fashion to avoid potential issues that may arise under the action of long-term solar exposure. Recent research has indicated that these daily and seasonal thermal cycles may induce shrinkage and potential loss of overlap at the edges of GCL panels when there is no cover soil (e.g. Koerner and Koerner 2005; Thiel and Richardson 2005; Bostwick et al. 2010; Rowe et al. 2011a; Rowe et al. 2013), and suppressed hydration of GCLs compared to hydration under isothermal conditions (e.g. Rayhani et al. 2011; Rowe et al. 2011b; Anderson et al. 2012; Chevrier et al. 2012; Siemens et al. 2012).

A field research project was initiated in 2006 by Queen's University to investigate the possible detrimental consequences of extended exposure of GMB/GCL composite liners. In the course of this research, a new failure mechanism, bentonite erosion caused by the formation of condensation at the GMB/GCL interface of an exposed composite landfill liner was identified. Similar to shrinkage, the energy source driving this new failure mechanism is solar exposure. It is well known that when left exposed to sunlight, the surface temperatures of black geomembranes can reach upwards of $70^{\circ} \mathrm{C}$ (Pelte et al. 1994; Take et al. 2015), causing significant thermal expansion and buckling (e.g. Giroud and Morel 1992; Take et al. 2012), and the formation of large networks of wrinkles in the exposed geomembrane (e.g. Rowe et al. 2004; Giroud 2005; Take et al. 2007; Chappel et al. 2012; Rowe et al. 2012a, 2012b). The air pockets below the geomembrane wrinkles act as an insulating layer, causing the wrinkles to reach a higher temperature than neighbouring liner material that is in direct contact with the underlying CCL or GCL (Take et al. 2015). Such exposure may help to explain field observations by Stark et al. (2004) of bentonite deposits near the base of a $24^{\circ}$ side slope lined with a GMB/GCL composite that was partially covered with water and attributed to down slope bentonite migration from the GCL. However, what has not been fully realised is the consequence of these thermal cycles driving a moisture cycle along the same principles that drive the operation of a solar still.

As shown in Figure 1a, the increase in temperature of the air between the interface of the GCL and geomembrane can cause water to evaporate from the GCL into the interface. As the afternoon progresses and the intensity of solar radiation acting on the geomembrane surface reduces, the temperature of the geomembrane will eventually drop below the temperature of the air space causing water vapour to condense on the underside of the

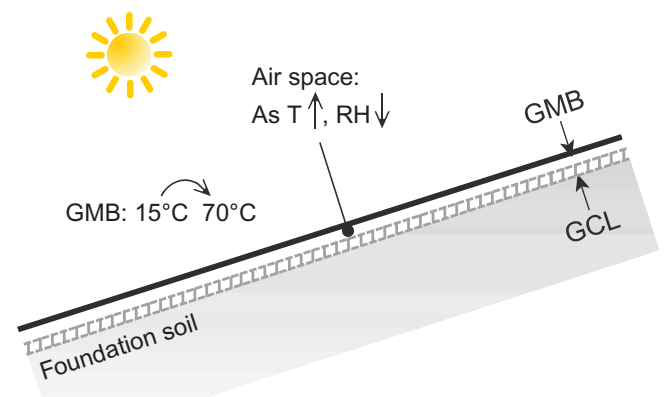

(a)

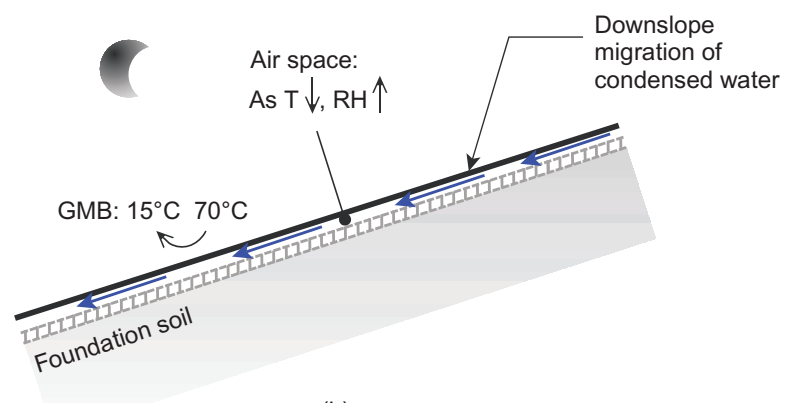

(b)

Figure 1. Solar-driven moisture cycle within the air gap between an exposed GMB and GCL: (a) daytime solar radiation heats black GMB to temperatures nearing $70^{\circ} \mathrm{C}$ which decreases the relative humidity $(\mathrm{RH})$ but increases the mass of water vapour in air space; ( b) evening cooling results in water vapour condensing on the cool underside of the GMB resulting in downslope migration of condensed water

geomembrane. Similar to the operating principle of a solar still, the formation of condensation on this inclined colder surface will result in droplets of distilled water flowing down the underside of the geomembrane until they collect at a drop point and, in the case of exposed composite liners, cause a targeted flow of water that leads to bentonite erosion if there a sufficiently long period of exposure.

The objective of this paper is to present the field observations of this failure mechanism for the four different GCL products underlying black high density polyethylene (HDPE) geomembrane in 11 unique test configurations at the Queen's University Environmental Liner Test Site.

\section{QUEEN'S UNIVERSITY EXPERIMENTAL LINER TEST SITE}

The Queen's University Environmental Liner Test Site (QUELTS) is located approximately $40 \mathrm{~km}$ north-northwest of Kingston, Ontario, Canada at latitude $44^{\circ} 34^{\prime} 15^{\prime \prime} \mathrm{N}$ and longitude $76^{\circ} 39^{\prime} 44^{\prime \prime} \mathrm{W}$ (Brachman et al. 2007). Constructed over the summer of 2006, GCLs were installed and covered by black $1.5 \mathrm{~mm}$ HDPE geomembrane between the 10th and 12th September 2006 and then left exposed to solar radiation for over 4 years with periodic inspections culminating in a final exhumation of geosynthetic products in June 2011.

The original QUELTS facility consisted of three barrier system configurations including a $21 \mathrm{~m}$ long by $76 \mathrm{~m}$ 
wide composite liner section installed at a slope of $3 \mathrm{H}$ : $1 \mathrm{~V}$ facing almost due south $\left(168^{\circ}\right.$ azimuth) to investigate the maximum impact of solar radiation, a $19.4 \mathrm{~m}$ long and $76 \mathrm{~m}$ wide base liner built with a gentle slope of $3 \%$ to the south to contrast this behaviour with that of a base liner, and a $20 \mathrm{~m}$ long by $76 \mathrm{~m}$ wide landfill liner cover section where the GCL products were covered by $0.7 \mathrm{~m}$ of cover soil. To achieve these three test sections a $46 \mathrm{~m}$ wide, $80 \mathrm{~m}$ long, and $6.3 \mathrm{~m}$ high earth embankment was constructed with a $5 \mathrm{~m}$ wide flat crest. The general arrangement of the site is shown in Figure 2. From this north-west looking view, the base liner and south facing slope portions of the embankment are visible with the black geosynthetic products corresponding to geomembranes and lighter coloured geosynthetic products corresponding to different GCL product types. At the time of the photograph, the smooth geomembrane was being deployed over four of the six GCL test sections on the base using the boom-lift shown in the far right of the photograph.

The arrangement of geosynthetic products and location of the various test sections is shown in the plan view of the QUELTS site in Figure 3. The south-facing slope consists of six test sections, with each test section consisting of three panels of GCL for a total of 18 GCL panels labelled S01-S18. Four different GCL products from two different manufacturers, referred to herein as GCL1 to GCL4 (Table 1), were installed at the site. The primary difference between these GCLs is their cover and carrier geotextiles and whether they have been subjected to thermal treatment. Another difference is the size of the bentonite granules. To enable a direct comparison between the four GCL products under typical geomembrane friction conditions found in practice for sloping installations, the middle four test sections of the south-facing slope correspond to three panels of each GCL product under textured geomembrane with an asperity height of $0.38 \mathrm{~mm}$ (see inset of Figure 3 for plan view of geomembrane product locations). The remaining two slope test sections, located at the far east and the far west of the south-facing slope, were covered with smooth geomembrane to allow an assessment of the effect, if any, of lower interface friction conditions on the long-term behaviour of GCL2 and GCL3 (i.e. influence of interface friction in wrinkle formation and panel shrinkage, etc.). In both the most western (GCL2) and most eastern (GCL3) test sections, the GCLs were installed with the nonwoven geotextile facing up to provided similar interface friction with the smooth geomembrane. This decision also allows a comparison of bentonite erosion in GCL3 when placed woven or nonwoven geotextile face up. GCL2 was only placed with the nonwoven cover geotextile facing upwards (i.e. no trial was conducted with the woven scrim-reinforced nonwoven facing up).

The base liner GCL layout comprised six test sections for a total of $18 \mathrm{GCL}$ panels labelled B01-B18. The arrangement of GCL products on the base section was the same as that on the south-facing slope, however, all GCL sections were overlain by a smooth geomembrane.

The north-most test section at QUELTS is the northfacing cover slope. Because this section was promptly covered after installation as per manufacturer's recommendations (in this case with the native silty-sand (SM) to represent a GCL cover slope) they are not included in this paper as they did not experience any solar-driven bentonite erosion.

During installation, adjoining GCL panels were placed with overlaps of $300 \mathrm{~mm}$ and supplemental bentonite. Adjacent geomembrane panels were joined with dual hot wedge thermal fusion seams. These seams were made with a wedge foot roller and all were tested using a dual seam positive air pressure test. Shear and peels tests on $25 \mathrm{~mm}$ wide and $100 \mathrm{~mm}$ coupons (ASTM D 4437) were conducted. The seams between the geomembrane on the slope and base were done with fillet extrusion welds tested with vacuum chamber tests. Once installed, both the GCLs and geomembranes were anchored around the perimeter in an anchor trench $0.5 \mathrm{~m}$ deep and $0.5 \mathrm{~m}$ wide. A continuous

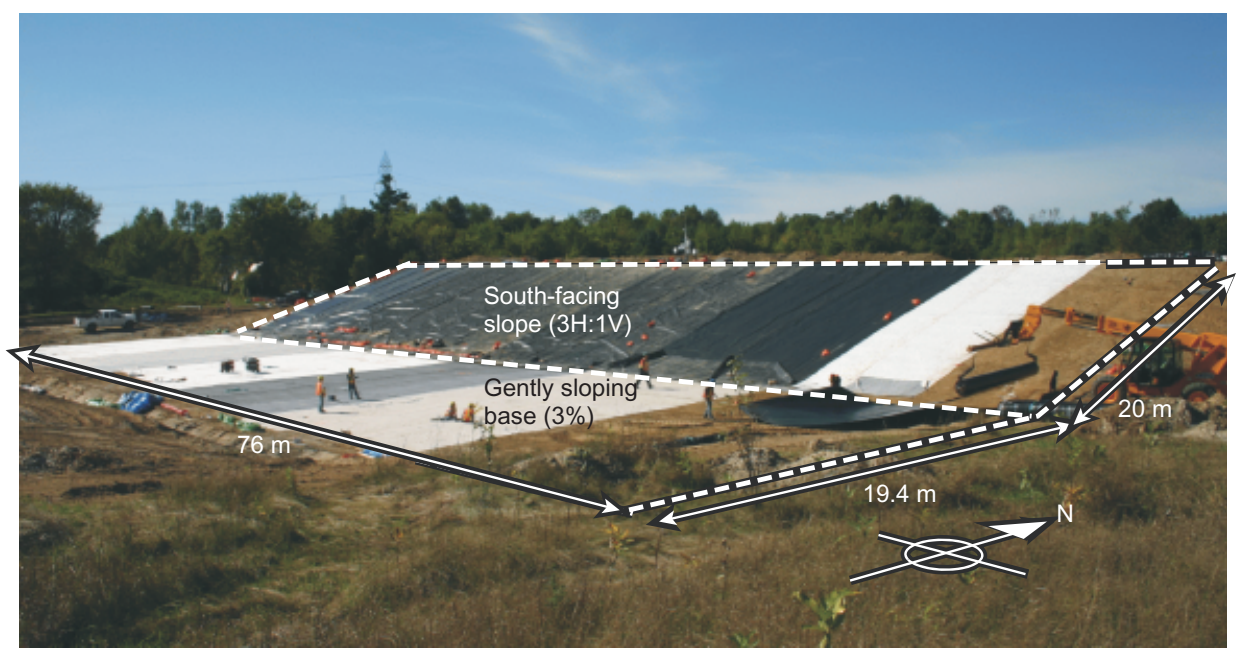

Figure 2. Construction of QUELTS test site. Test site consists of a south facing $3 \mathrm{H}: 1 \mathrm{~V}$ slope and a gently sloping base section. At the time of the photograph the smooth GMB was being deployed over four of the six GCL test sections on the base. Variations in GCL colour correspond to different GCL product test sections 


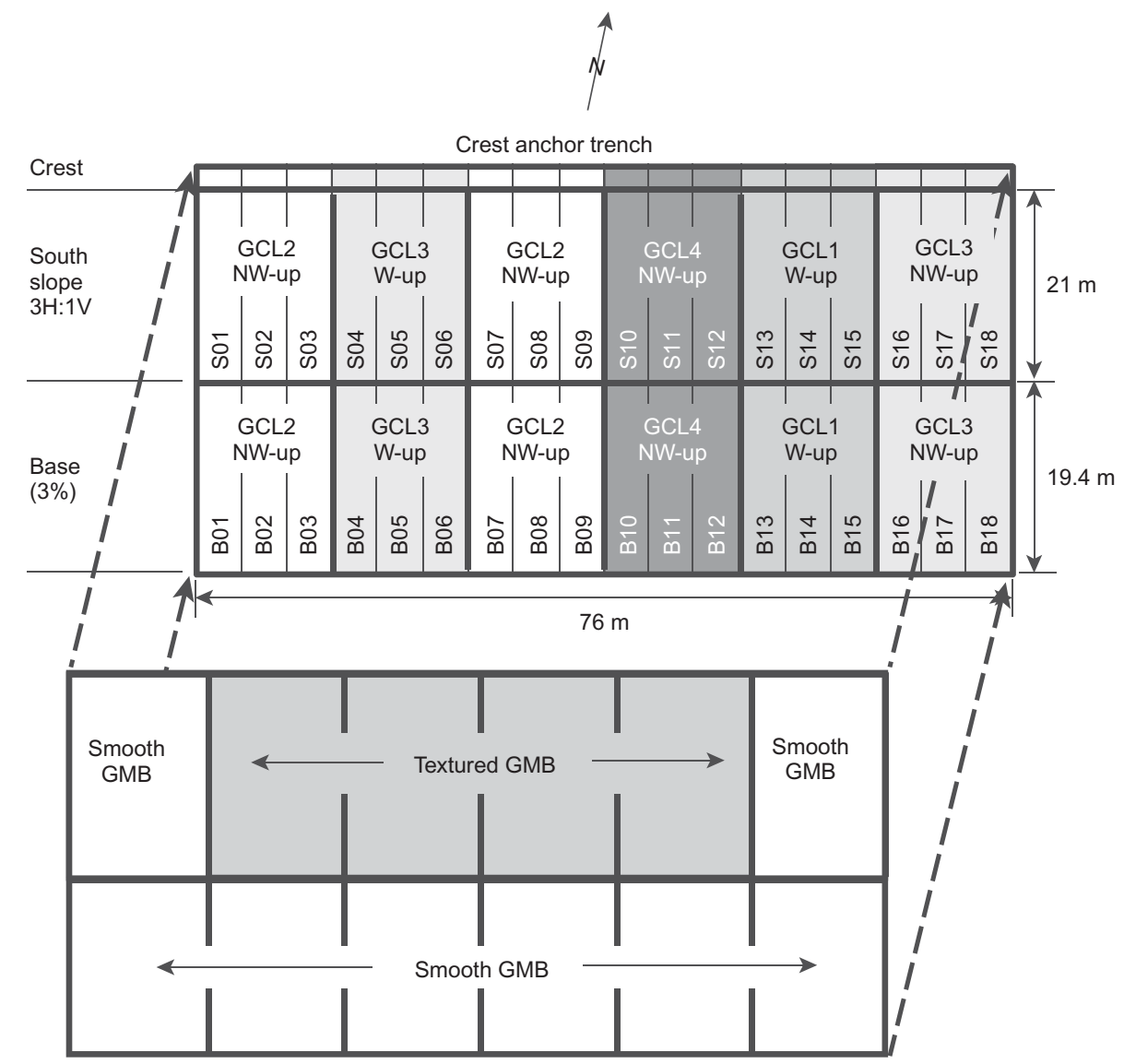

Figure 3. Plan view of QUELTS test site illustrating location of four GCL products and two overlying GMB types installed on both the slope and base, yielding 11 unique test configurations. Top surface of GCL identified as nonwoven geotextile up (NWup) or woven geotextile up (W-up)

Table 1. Properties of needle-punched GCLs installed at QUELTS as measured by Bostwick (2009)

\begin{tabular}{|c|c|c|c|c|c|c|c|c|c|c|c|}
\hline \multirow[t]{2}{*}{$\begin{array}{l}\text { Product } \\
\text { name }\end{array}$} & \multicolumn{3}{|c|}{$\begin{array}{l}\text { Total GCL mass per unit area } \\
\qquad\left(\mathrm{g} / \mathrm{m}^{2}\right)\end{array}$} & \multirow[t]{2}{*}{$\begin{array}{l}\text { Carrier } \\
\text { GTX }^{\mathrm{b}}\end{array}$} & \multicolumn{2}{|c|}{$\begin{array}{l}\text { GTX mass per unit } \\
\text { area }\left(\mathrm{g} / \mathrm{m}^{2}\right)\end{array}$} & \multirow[t]{2}{*}{$\begin{array}{l}\text { Cover } \\
\text { GTX }^{\mathrm{b}}\end{array}$} & \multicolumn{2}{|c|}{$\begin{array}{l}\text { GTX mass per unit } \\
\text { area }\left(\mathrm{g} / \mathrm{m}^{2}\right)\end{array}$} & \multirow[t]{2}{*}{ Bentonite type } & \multirow[t]{2}{*}{$\begin{array}{l}\text { Thermal } \\
\text { treatment }\end{array}$} \\
\hline & $\begin{array}{l}\text { Mean } \\
\text { value }\end{array}$ & $\begin{array}{l}\text { Standard } \\
\text { deviation }\end{array}$ & MARV $^{a}$ & & $\begin{array}{l}\text { Mean } \\
\text { value }\end{array}$ & $\begin{array}{l}\text { Standard } \\
\text { deviation }\end{array}$ & & $\begin{array}{l}\text { Mean } \\
\text { value }\end{array}$ & $\begin{array}{l}\text { Standard } \\
\text { deviation }\end{array}$ & & \\
\hline GCL1 & 4968 & 93 & 3965 & W & 123 & 2 & NW & 242 & 16 & Fine granular & Yes \\
\hline GCL2 & 4370 & 357 & 4060 & SRNW & 260 & 21 & NW & 232 & 20 & Fine granular & Yes \\
\hline GCL3 & 5640 & 422 & 4008 & W & 125 & 5 & NW & 283 & 43 & Coarse granular & No \\
\hline GCL4 & 4830 & 188 & 4097 & NW & 233 & 39 & NW & 264 & 39 & Coarse granular & No \\
\hline
\end{tabular}

${ }^{\text {a }}$ Calculated based on manufacturers published MARV (minimum average roll value) for bentonite and cover and carrier geotextiles.

${ }^{\mathrm{b}} \mathrm{W}$, woven; NW, nonwoven; SRNW, scrim reinforced nonwoven.

line of sandbags was permanently placed on top of the geomembrane at the toe of the south slope.

\section{FIELD INSPECTION METHODS}

The objectives of QUELTS was to simultaneously investigate the impact of long-term solar exposure on seasonal geomembrane temperature cycles (Take et al. 2015), the resulting formation of interconnected wrinkle networks (Rowe et al. 2012a), seasonal moisture uptake and retention behaviour of GCLs and GCL panel shrinkage. Of these investigations, the wrinkle formation study in particular required that the geomembrane be left as unaltered as possible over the duration of the study to avoid observer effects influencing the wrinkle network. As a result, the periodic measurements of changes in GCL panel overlap and GCL and silty-sand foundation soil moisture content were typically taken through small $300 \mathrm{~mm}$ square openings in the geomembrane. Once the data collection for the wrinkle network study was completed in August 2009, a revised periodic monitoring programme was adopted in which three cuts in the geomembrane were used to simultaneously expose all three of the GCL panels of each test section. This new strategy allowed the entire surface area of the GCL to be inspected by hand and for high resolution images of the 
GCL panels to be captured using high resolution digital photography (Figure 4) using the helium-filled airship described by Take et al. (2007).

\section{IDENTIFICATION OF BENTONITE EROSION}

The ability to inspect the entire GCL panel enabled observations of downslope streaking and colour variations in the GCLs on the slope and the full extent of bentonite deposition to be observed on the surface of GCLs on the base liner. Curiosity regarding the origin of these features led to the discovery of bentonite erosion during the fullpanel inspection of the GCLs in May 2010 (i.e. after 3.6 years of the composite liner or exposure). A photograph of one of these streaks in a $1520 \mathrm{~mm} \times 610 \mathrm{~mm}$ section of GCL2 selected for sampling at the bottom of panel S02 at this time is shown in Figure 5a. In this image, the grey colour of the GCL corresponds to areas of the GCL where the surface of the cover GTX has been impregnated with bentonite within the nonwoven GTX during field exposure. Areas with a whiter colour are locations where the nonwoven cover GTX has been washed by downslope moisture migration to reveal the original cleaned colour of the GTX (i.e. white). Tactile inspection of the grey areas by applying gentle hand pressure revealed that the GCL at the location of these bentonite-impregnated areas of the cover GTX were hard, consistent with a stiff low moisture content GCL (i.e. desiccated). In contrast, the zones washed clean of bentonite to reveal the original colour of the cover GTX felt soft and deformable similar to a GTX alone; these locations felt like they did not have any bentonite present. Samples of two of these features were retrieved and the internal distribution of bentonite was recorded non-destructively using X-ray imaging.

$\mathrm{X}$-ray images were captured using a $65 \mathrm{kV}$ X-ray facility at the Cancer Centre of Southeastern Ontario using the methodology described by Take et al. (2012). This facility consists of a 2048 pixel $\times 1536$ pixel imaging panel with physical dimensions of $400 \mathrm{~mm} \times 300 \mathrm{~mm}$ located $1.19 \mathrm{~m}$ from the radiation source. In this configuration the pixel width of the X-ray images was

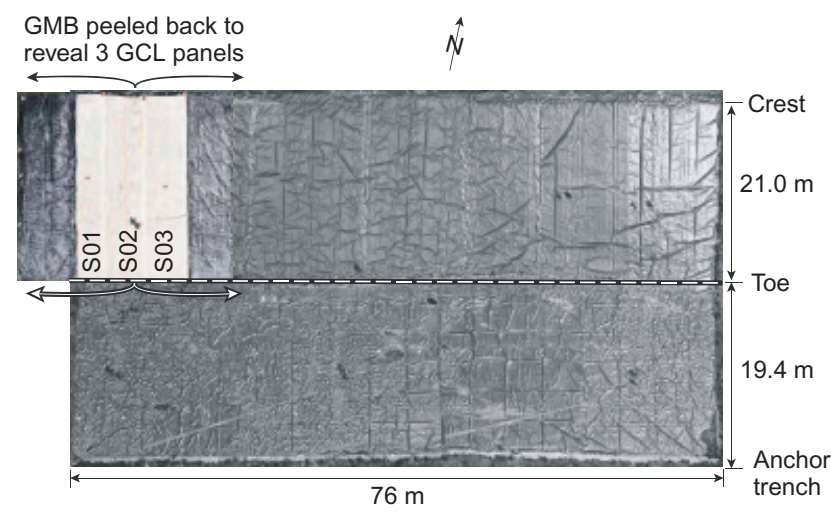

Figure 4. Full-panel inspection of GCL test sections S01-S03. Three cuts in the GMB were used to peel back the GMB to reveal three GCL panels at a time for inspection, measurement, and subsequent aerial photography
$0.194 \mathrm{~mm}$. Owing to the large relative size of the erosion feature $(1520 \mathrm{~mm} \times 610 \mathrm{~mm})$ compared to the imaging panel, the erosion sample was subdivided into five $305 \mathrm{~mm} \times 610 \mathrm{~mm}$ subsamples for X-raying. The bottom $25.4 \mathrm{~mm}$ of each of these sub-samples was then used to create $25.4 \mathrm{~mm}$ square moisture and bentonite content samples. As a result, the final $280 \mathrm{~mm} \times 610 \mathrm{~mm}$ size of each subsample enabled the subsample to be imaged in two X-rays with sufficient image overlap to subsequently be digitally stitched together to form a complete image. The resulting X-ray image of the full $1520 \mathrm{~mm} \times 610 \mathrm{~mm}$ erosion feature is shown in Figure $5 \mathrm{~b}$. Dark pixels in the $\mathrm{X}$-ray image correspond to low attenuation of X-rays indicating very low bentonite content, whereas lighter pixels correspond to higher attenuation through higher bentonite regions. Two main erosion features can be seen in the image; a large erosion feature in the centre of the image which runs downslope along the full length of the $1520 \mathrm{~mm}$ long erosion sample, and a smaller feature on the left-hand side of the image. A comparison of the X-ray image with the visual photograph of the sample presented in Figure 5a confirms that, for this particular GCL product, the presence of a white-coloured top GTX washed free of bentonite indicates that bentonite erosion may have occurred in this product. However, there are areas where the surface GTX of the GCL is white, but the $\mathrm{X}$-ray image indicates that bentonite still remains inside the GCL. Thus visual inspection gives a clue that erosion may have occurred for this product but it does not mean that all the bentonite is eroded.

The X-ray images provided an excellent overview of the distribution of bentonite mass. The five cross-sections of moisture and bentonite content samples labelled A-A' through $\mathrm{E}-\mathrm{E}^{\prime}$ in Figure $5 \mathrm{~b}$ enable a quantitative evaluation of the mass of bentonite remaining (and by comparison with the original value the amount eroded) across the sample. The gravimetric moisture content profiles generated from these 120 subsamples are presented in Figure 5c. This data indicates that the desiccated areas in the X-ray image corresponds to a gravimetric moisture content of approximately $16 \%$ and the moisture content of the eroded areas ranges from 1 to $5 \%$. The moisture content profiles at cross-sections A-D are broadly consistent, whereas the cross-section taken at the transition to the base liner (section E) has a localised higher moisture content zone. Using this data, and the mass per unit area of the two GTX components of each GCL listed in Table 1 , the dry mass of bentonite per unit area was calculated and is presented in Figure $5 \mathrm{~d}$. This presentation of the data clearly indicates the loss of bentonite in the low attenuation zones seen in the X-ray and identified by the tactile survey. The mean dry bentonite mass per unit area for virgin samples of GCL2 was $3878 \mathrm{~g} / \mathrm{m}^{3}$. In regions where no erosion was identified, the measured value for the exhumed specimen was consistent with the mean value observed for this GCL. However, in eroded regions the measured values were observed to drop as low as $92 \mathrm{~g} / \mathrm{m}^{3}$ which, considering the difficulty in measuring this parameter in small-scale sub-samples, was effectively zero bentonite content. The large width of the low bentonite 


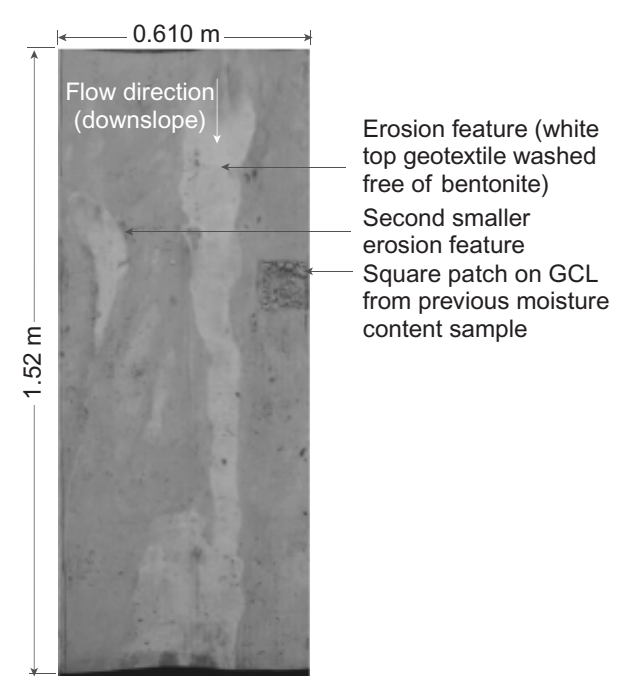

(a)

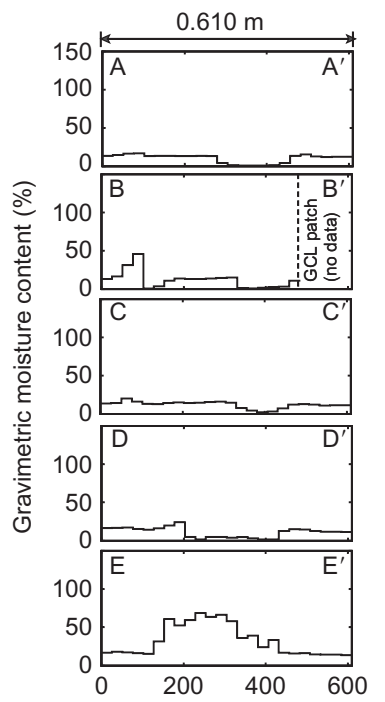

(c)

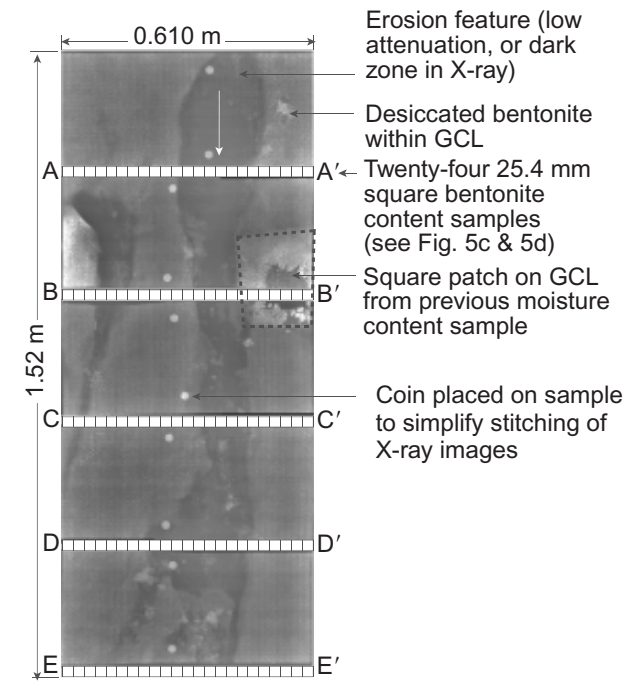

(b)

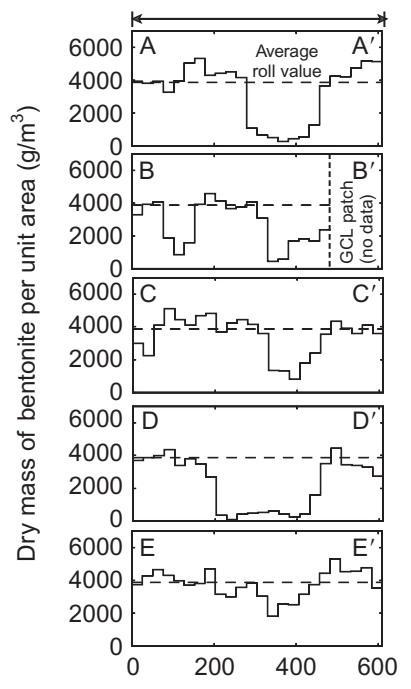

(d)

Figure 5. (a) Photograph of 2010 GCL2 erosion sample after 3.6 years beneath an exposed smooth black GMB. In this product, white areas denote low bentonite content in cover geotextile, which may signify bentonite erosion from within the GCL. (b) X-ray image of 2010 GCL2 erosion sample. Dark pixels in the image correspond to little to no attenuation of X-rays and low bentonite content, whereas lighter pixels correspond to higher attenuation through higher bentonite content regions. (c) Gravimetric moisture content of 2010 GCL2 sample measured at cross-sections A, B, C, D and E. (d) Dry mass of bentonite per unit area measured at cross-sections A, B, C, D and E of 2010 GCL2 erosion sample compared to measured average roll value

content erosion feature (e.g. greater than $200 \mathrm{~mm}$ across in cross-section D) was sufficient to make it unlikely to be self-healed upon hydration and the application of stress. As a result, the observed erosion behaviour would have severe adverse consequences for leakage rates through the GCL component of a composite liner barrier system.

The difficulty in using visual appearance to identify erosion zones is further illustrated using a second erosion sample taken from GCL3 in May 2010. The photograph of this product shows a washed area of the top GTX (Figure 6a) which is also shown to be a location of bentonite loss by the X-ray image (Figure 6b). However, the X-ray image and subsequent moisture content and bentonite content results (Figures 6c and 6d) indicate that the size of the erosion zone was much larger than simply the lightest colour zone in Figure 6a. These observations indicate that colour alone is not a sufficient indicator of the presence of erosion. Therefore, in this project, erosion was identified by having a field team conduct a tactile inspection of the full surface area of each GCL section to feel for the presence of bentonite. This methodology was highly effective in identifying areas of major bentonite erosion and areas where the GCL was stiff due to rigid desiccated bentonite within the GCL. An example of this high contrast in stiffness to touch is shown in the sharp transition between bentonite free zones and desiccated zones in the GCL X-rays of Figure $5 b$ and $6 b$.

\section{TACTILE SURVEY RESULTS OF GCL EROSION}

Upon the discovery of erosion at QUELTS after 3.6 years of field exposure in May 2010 the site was revisited in June 2011 to conduct a full tactile inspection of the 12 


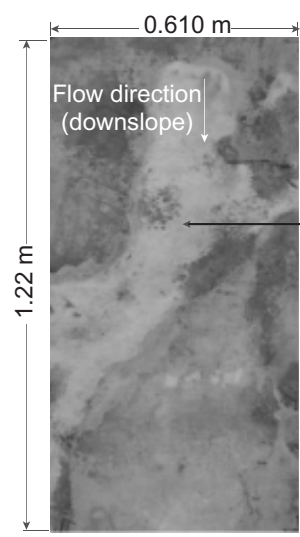

(a)

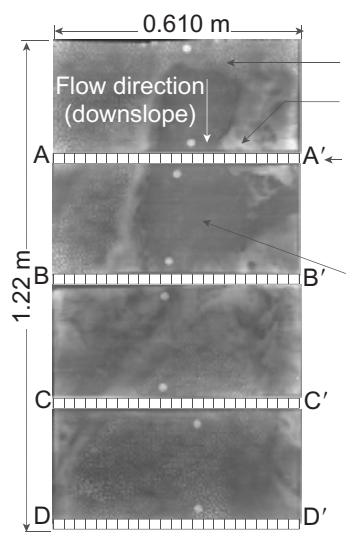

(b)

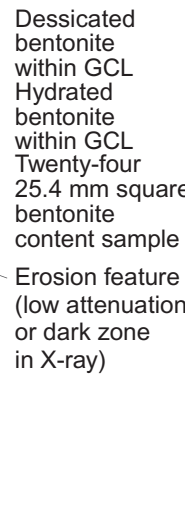
bentonite within GCL bentonite within GCL $5.4 \mathrm{~mm}$ square content sample (white top geotextile washed free of bentonite)

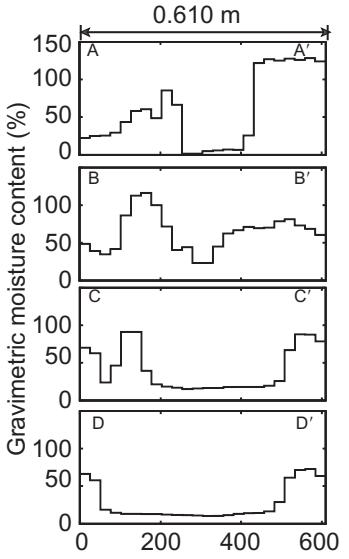

(c)

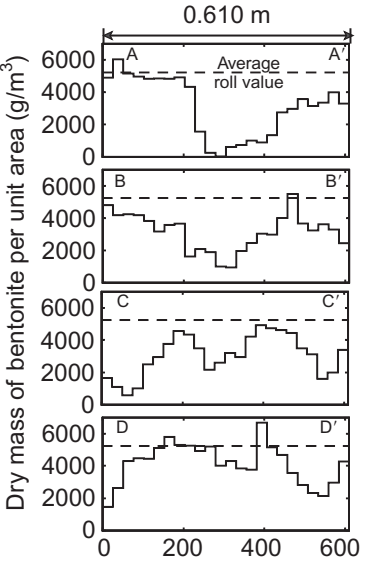

(d)

Figure 6. (a) Photograph of 2010 erosion sample taken from GCL3 after 3.6 years beneath an exposed smooth black GMB. In this product, white areas denote low bentonite content in top geotextile. (b) X-ray image of large erosion feature identified in GCL3 in 2010. Dark pixels in the image correspond to little to no attenuation of X-rays and low bentonite content, whereas lighter pixels correspond to higher attenuation through higher bentonite content regions. (c) Gravimetric moisture content of GCL3 erosion sample measured at cross- sections A,B,C, and D. (d) Dry mass of bentonite per unit area observed at crosssections A, B, C and D in GCL3 erosion sample compared to measured average roll value

exposed composite liner sections. The objective of the June 2011 inspection was to assess the extent of erosion damage to the GCL panel test sections after 4.7 years of exposure. To achieve this goal, the field team was trained to perform tactile inspections for GCL bentonite erosion and identified features were outlined in orange spray paint so that the number, location and approximate size of the larger erosion features could be recorded in high-resolution air photos taken using a remotely triggered camera flying overhead in a tethered helium-filled airship.

The results of these tactile inspections are discussed in this section of the paper, beginning with GCL2. GCL2 is a needle-punched, thermally-treated GCL with a nonwoven cover GTX and composite nonwoven and woven carrier GTX (i.e. scrim-reinforced) which has a different water retention curve from the other three products (Beddoe et al. 2010, 2011). This product's white top GTX enabled the easiest identification of possible erosion locations based on the colour of the exhumed GCL surface (e.g. Figure 5a). An air photo of the first test section of GCL2 (panels S01-S03) that were covered with a smooth black geomembrane is presented in Figure 7. In this image the orange spray paint marks on the GCL denoting detected zones of bentonite erosion have been digitally highlighted with a black line to increase the clarity of the figure when printed in black and white. This image indicates that significant bentonite erosion had occurred in each of the three GCL panels during the 4.7 years of exposure. A total of 127 erosion features were detected. Isolated erosion holes were observed to generally have a 'tadpole shape' in which the erosion hole was wider towards the upslope side and an eroded tail that narrowed towards the downslope side of the feature. In some areas multiple erosion holes were observed to join together to form a wider upslope erosion hole with multiple downslope erosion pathways (e.g. the feature approximately $1.6 \mathrm{~m}$ across the panel and $14.5 \mathrm{~m}$ from the top of the slope in Figure 7). The most striking erosion feature observed on these panels, however, was

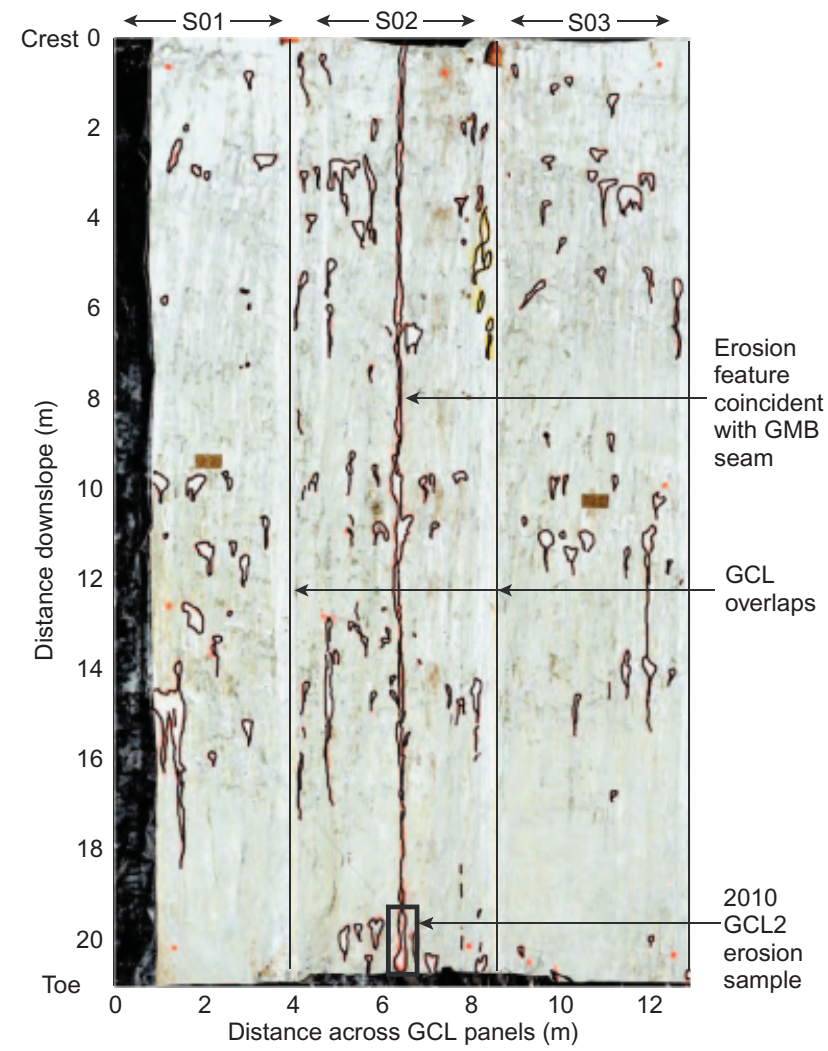

Figure 7. Erosion of bentonite detected in 2011 tactile survey of GCL2 installed on a south-facing slope and covered with a smooth GMB (panels S01-S03) after 4.7 years beneath an exposed black GMB

coincident with the location of the downslope geomembrane seam. At this location, an erosion feature was observed to extend the entire $21 \mathrm{~m}$ length of the GCL panel, from the crest to the toe of the slope. It can be seen at a distance of approximately $6 \mathrm{~m}$ from the west edge of the GCL panels in Figure 7. This erosion feature was typically $90 \mathrm{~mm}$ wide but was as wide as $330 \mathrm{~mm}$ at 
around $11 \mathrm{~m}$ from the top of the slope. This feature suggests that condensation running downslope can preferentially be collected at the location of geomembrane seams and give rise to more severe bentonite erosion. The 2010 erosion sample of GCL2 discussed in Figure 5 was obtained from the bottom of panel S02, where this erosion feature met the base of the slope.

The air photo for the base panels of GCL2 at this location (panels B01-B03) are shown in Figure 8. This image shows surficial deposition of grey bentonite gel on the top surface of GCL panel B03 over the full $19.4 \mathrm{~m}$ length of the base liner. In panels B01 and B02 this bentonite gel was mixed with a small amount of brown silt, due to a small amount of foundation soil spilt onto panel B01 during construction of the anchor trench. In addition to the deposition of bentonite on the surface of the GCL, 17 erosion features were detected on Panel B03 (Figure 8). The erosion features on the base within $1 \mathrm{~m}$ of the toe of the slope were observed to be coincident with a cross-slope geomembrane seam. Again, this observation indicated that geomembrane seams may serve to collect downslope migrating condensation and increase the flow of water reaching a specific point of the GCL. The erosion features identified at 7.2, 13.9 and $16.7 \mathrm{~m}$ from the toe of the slope were directly beneath roll-direction wrinkles in the overlying geomembrane. (Note that, for construction convenience to the installer, on the base, the geomembrane was installed such that its roll direction was perpendicular to the roll direction of the GCL.)

To investigate whether geomembrane roughness impacted bentonite erosion, the air photo of identified erosion

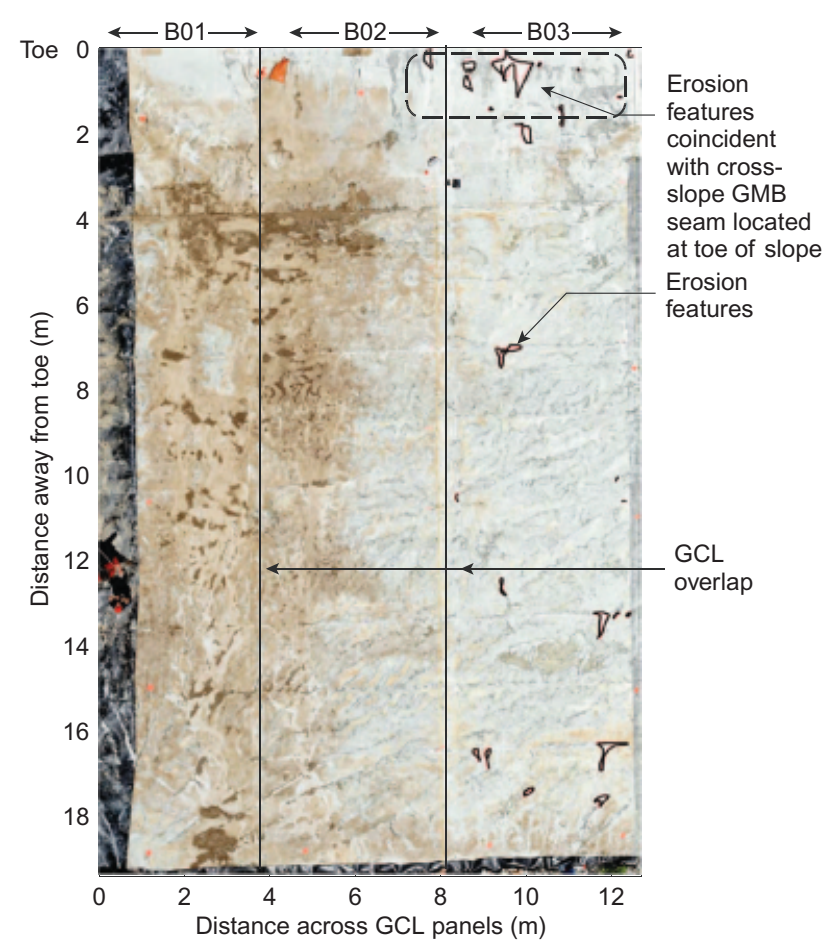

Figure 8. Erosion of bentonite detected in 2011 tactile survey of GCL2 installed on the base (panels B01-B03) after 4.7 years beneath an exposed black GMB. Erosion on the base was observed to be less severe than the slope with considerable deposition of bentonite paste on top of the GCL features for GCL2 is shown in Figure 9, but this time when placed under a textured geomembrane (panels S07-S09). A visual comparison of the erosion features observed in GCL2 under the smooth geomembrane (Figure 7) and the textured geomembrane (Figure 9) indicated that the degree of bentonite erosion was similar under both of these geomembranes. Thus for this product, there was no significant difference between the erosion of GCL2 covered by either smooth or textured geomembrane. Although surficial deposition of bentonite on the top surface of the GCL on the base was again extensive, no erosion features were observed on the base panels of this test configuration (panels B07-B09).

Figure 10 shows an aerial view of panels S10-S12 which involved GCL4, a needle-punched GCL made with nonwoven cover and carrier GTXs but without thermal treatment. As placed, the upper GTX of this product was black, which made visual identification of potential erosion features much more difficult than for GCL2 and it is highly likely that there were erosion features in GCL4 that went undetected. For example, spot checks conducted after the initial visual and tactile inspection of GCL4 found that in $50 \%$ of the random locations examined along a line across an entire panel width (i.e. not selected because there was a visual hint) there was no bentonite over a distance of at least $25 \mathrm{~mm}$ when the geotextile was cut to ascertain whether or not there was bentonite present. Consequently, the erosion features identified in Figure 10 is an underestimate of the frequency of erosion features.

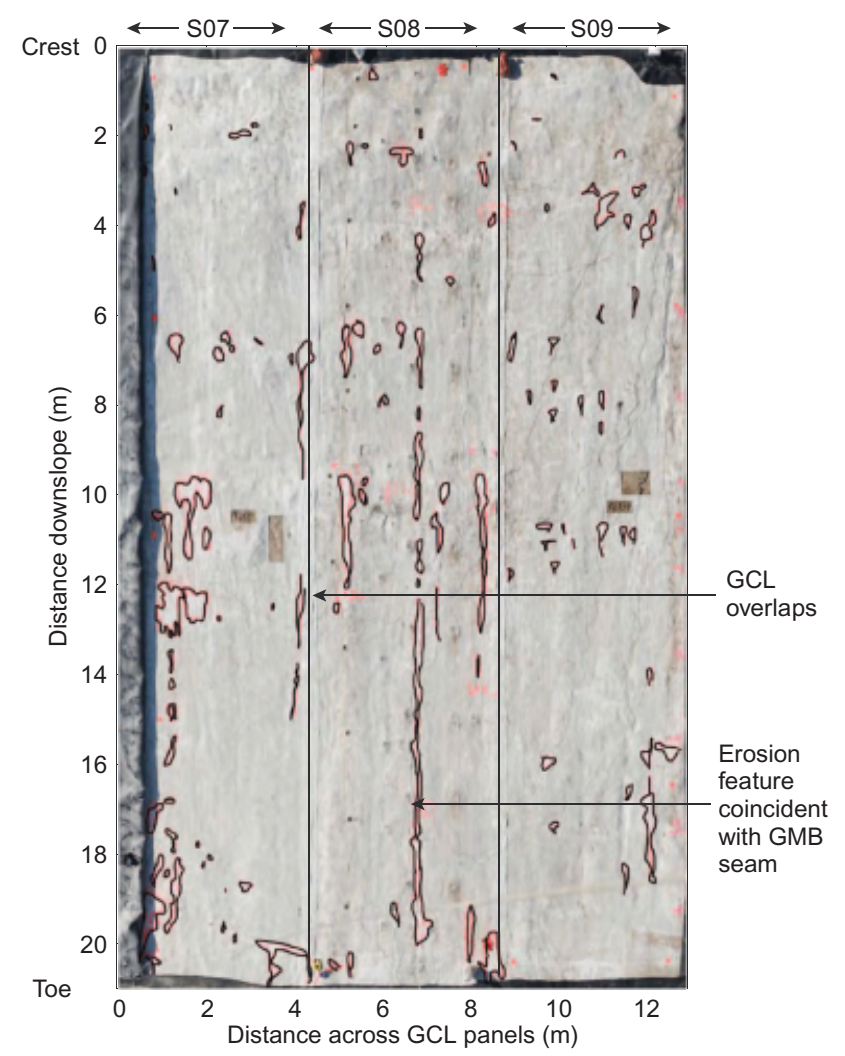

Figure 9. Erosion of bentonite detected in 2011 tactile survey of GCL2 installed on a south-facing slope and covered with a textured GMB (panels S07-S09) after 4.7 years beneath an exposed black GMB

Geosynthetics International, 2015, 22, No. 1 


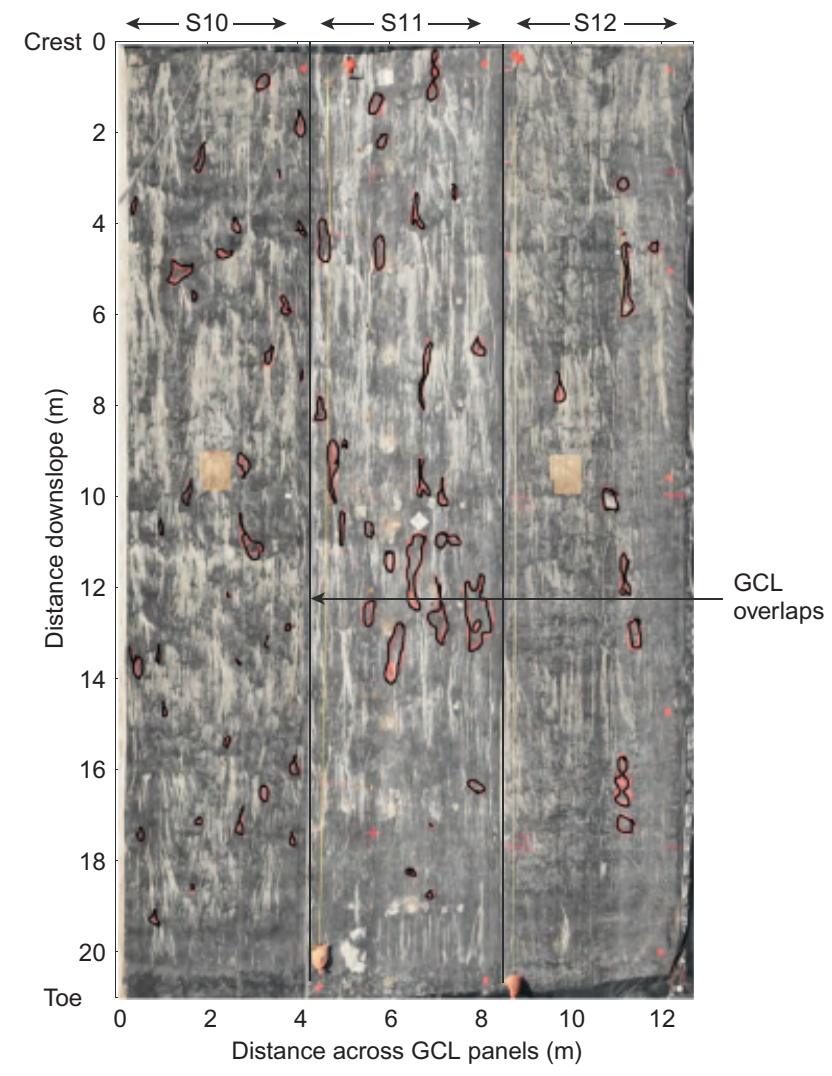

Figure 10. Erosion of bentonite detected in 2011 tactile survey of GCL4 installed on a south-facing slope and covered with a textured GMB (panels S10 -S12) after 4.7 years beneath an exposed black GMB. Because of the difficulty in detecting erosion features on GCLs with a black geotextile facing upwards, the number of features shown is likely an underestimate of the total number of erosion features

Despite this, seventy erosion features were detected on panels S10-S12. The largest detected feature was $1.5 \mathrm{~m}$ long and $0.5 \mathrm{~m}$ wide. The dark colour of the upper GTX of GCL4 did provide a high-contrast dark background on which the light-coloured streaks of bentonite that has moved downslope could be easily identified (Figure 10). These bentonite streaks were observed to be roughly uniformly distributed over the GCL surface area; however, the locations of these streaks were not necessarily correlated with the location of erosion features from the tactile survey.

Figure 11 shows an aerial photograph of GCL4 on the base section highlighting a long and narrow feature without bentonite detected on panel B12 that essentially extended along the entire base section. This feature was nearly $18 \mathrm{~m}$ long and $25-50 \mathrm{~mm}$ wide. An erosion feature (approximately $560 \mathrm{~mm}$ long $\times 75 \mathrm{~mm}$ wide) beneath a roll direction geomembrane wrinkle was also detected on panel B12, located approximately $6.3 \mathrm{~m}$ from the toe of the slope. After detecting and documenting the long feature on panel B12, only a cursory visual and tactile examination of panels B10 and B11 were conducted and are hence not shown in Figure 11.

As the bentonite erosion mechanism involves the surficial flow of water over the top of the GCL, it is possible that GCLs with different top GTXs may have a

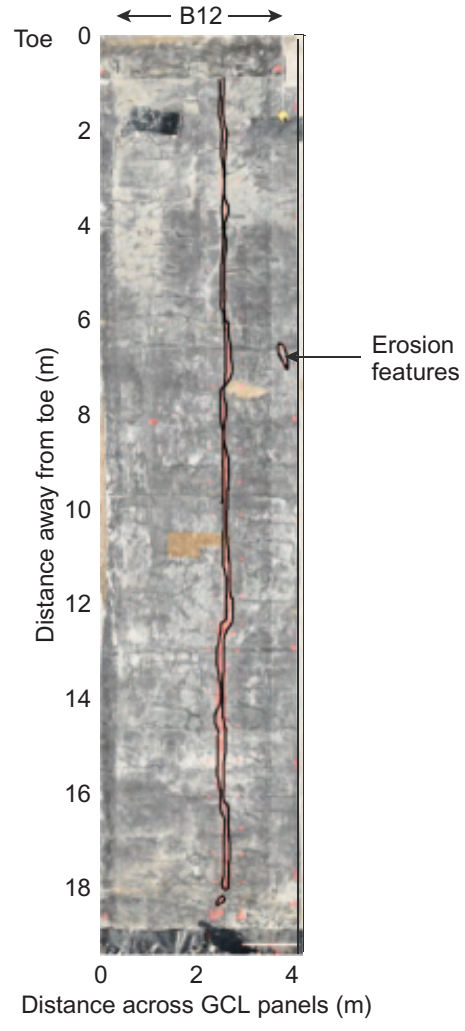

Figure 11. Erosion of bentonite detected in 2011 tactile survey of GCL4 installed on the base (panel B12) after 4.7 years beneath an exposed black GMB. Because of the difficulty in detecting erosion features on GCLs with a black geotextile facing upwards, the number of features shown is likely an underestimate of the total number of erosion features

different susceptibility to erosion. The GCL1 test section provides an interesting opportunity to investigate this idea. GCL1 is a needle-punched and thermally-treated GCL with a nonwoven cover geotextile and a slit-film woven carrier geotextile. It was placed with its woven geotextile facing up. The air photo for this test section (Figure 12; panels S13-S15) shows fewer and smaller bentonite erosion features than in either GCL2 or GCL4. Despite the fewer number of features (38 were detected), GCL1 still had erosion features that would be significant in terms of its hydraulic performance. The largest detected feature was on panel S5 and was approximately $1 \mathrm{~m}$ long and $0.2 \mathrm{~m}$ wide.

The GCL3 test sections enable another more direct comparison to be made between the influence of the upper (top) GTX on bentonite erosion. GCL3 is a needlepunched GCL with a nonwoven on one side and a slit-film woven GTX on the other. In one test section (panels S04S06) this product was placed with the black woven GTX up (Figure 13) whereas in a second test section the product was placed with the white nonwoven GTX up (Figure 14; panels S16-S18). There were nearly four times more erosion features detected with the nonwoven GTX up than with the woven GTX up (94 versus 24 features). Although it appears that downslope erosion was less extensive with the woven geotextile up, there may be no practical difference after 4.7 years of exposure given that 


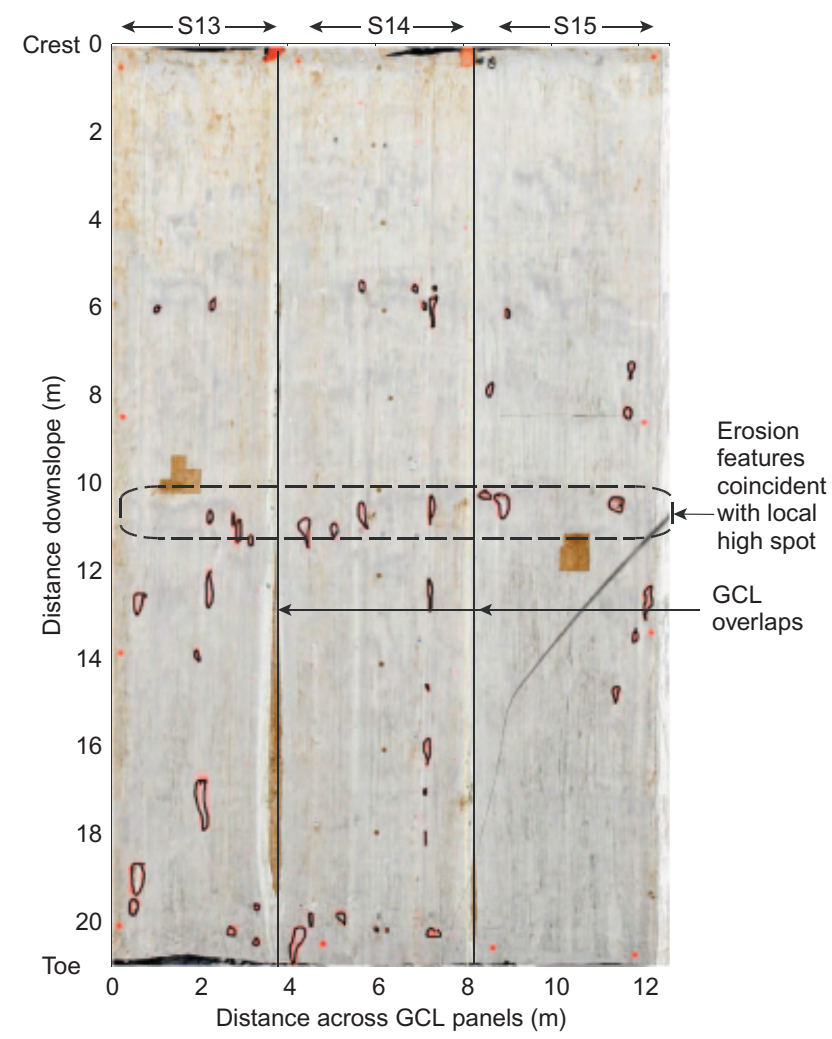

Figure 12. Erosion of bentonite detected in 2011 tactile survey of GCL1 installed on a south-facing slope and covered with a textured GMB (panels S13-S15) after 4.7 years beneath an exposed black GMB

the features identified in Figure 13 would most likely negatively impact the hydraulic effectiveness of the GCL. It is unknown whether this would translate into better performance after say 6 months of exposure by having the slit-film woven geotextile up.

In terms of woven versus nonwoven geotextile facing up on the base, no erosion features were observed for GCL1 or GCL3 with their slit-film woven geotextiles facing up (B13-B15 and B04-B06 as shown in Figure 15a and 15b, respectively), whereas 15 erosion features were detected on the base panels of GCL3 with its nonwoven geotextile facing up (B16-B18) as shown in Figure 16.

The previous comparison of GCL3 on the side slope with its woven and nonwoven geotextiles facing up also involves a difference in geomembrane as the woven-up case in Figure 13 had a textured geomembrane whereas the nonwoven-up case in Figure 14 has a smooth geomembrane. It is thought that the choice of the top GTX is the primary cause of the difference in behaviour for two reasons. First, a direct comparison between GCL2 under the smooth and the textured geomembrane showed similar results between these two test sections. Second, the base liner panels of these two sections (both covered by a smooth geomembrane) showed considerable differences in erosion behaviour.

Overall, most of the detected erosion features appeared to be coincident with some sort of irregularity induced either by the geomembrane or foundation soil, as indicated in Figures 7-16. These were related to down- and cross-

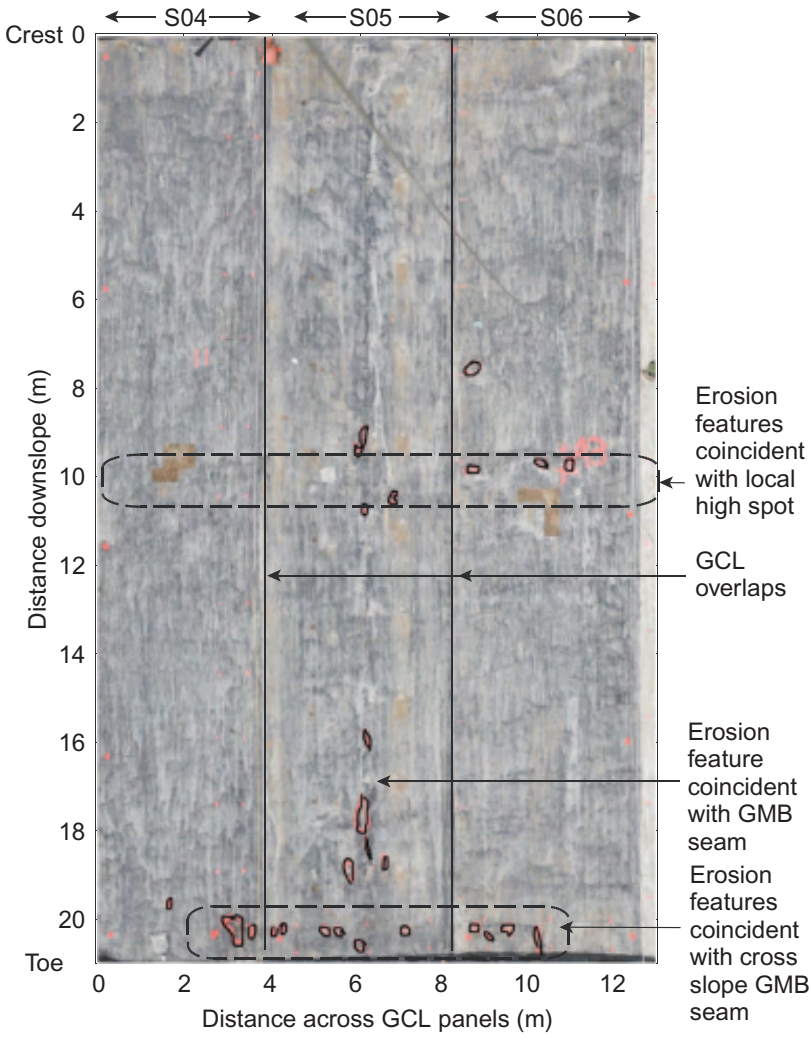

Figure 13. Erosion of bentonite detected in 2011 tactile survey of GCL3 installed woven-up on a south-facing slope and covered with a textured GMB (panels S04-S06) after 4.7 years beneath an exposed black GMB. Because of the difficulty in detecting erosion features on GCLs with a black geotextile facing upwards, the number of features shown is likely an underestimate of the total number of erosion features

slope wrinkles in the geomembrane, local very minor high-spots in the foundation soil beneath the GCL (well within the normally specified limits), and geomembrane seams and patches that were oriented either along or across the slope. Figure 17 schematically illustrates some of these irregularities and how they may impact the flow of condensed water vapour flowing along the interface between the geomembrane and GCL.

\section{TIME TO EROSION}

All four GCL products were observed to have experienced significant bentonite erosion after being covered only by a black geomembrane and left exposed for 4.7 years. This begs the question 'how quickly does it take for erosion occur?' as this directly impacts the length of time composite liners can be safely left exposed to solar radiation. Unfortunately, due to the nature of this field experiment, the bentonite erosion failure mechanism was not identified until after 3.6 years of exposure. However, the large samples taken at the time of the first discovery of the erosion in May 2010 enable an upper bound to be made on the length of time before erosion occurs. This is because the large samples discussed in Figures 5 and 6 were patched with virgin GCL materials at that time, 


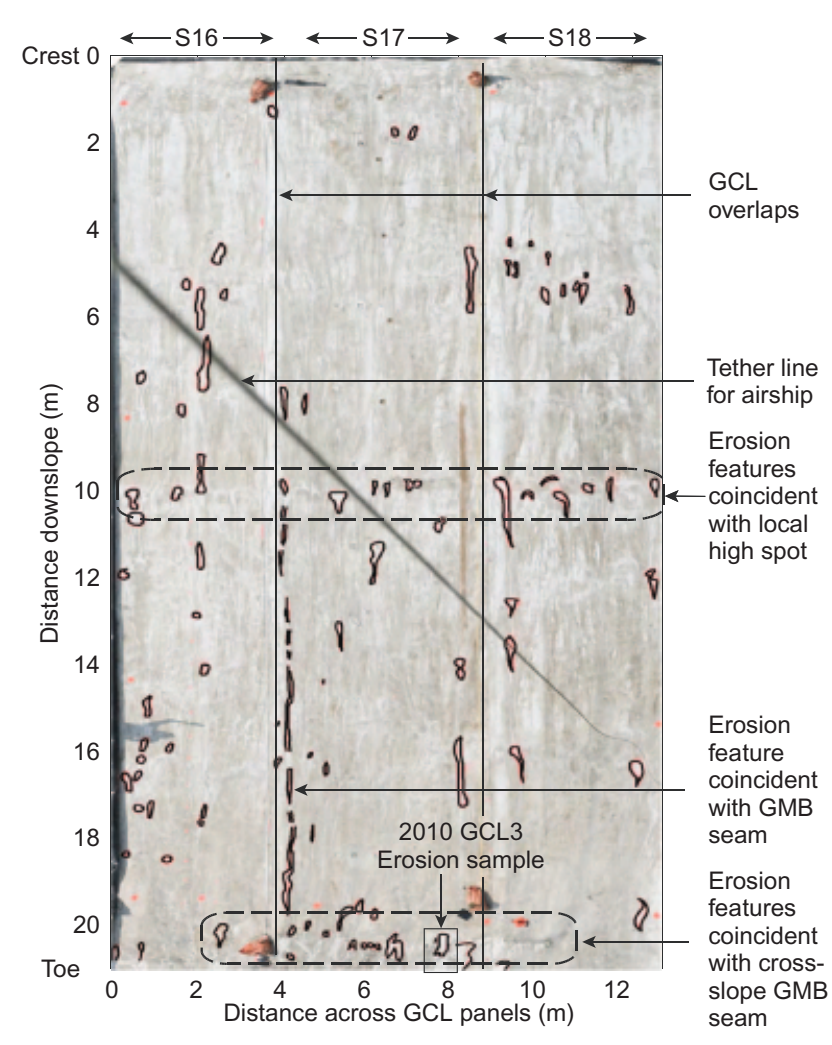

Figure 14. Erosion of bentonite detected in 2011 tactile survey of GCL3 installed nonwoven GTX facing up on a south-facing slope and covered with a smooth GMB (panels S16-S18) after 4.7 years beneath an exposed black GMB

effectively resetting the erosion clock at these locations. These patches were then subsequently exhumed after 1 year of exposure during the full tactile survey performed in June 2011. Visual images of the 2010 erosion samples and the 2011 erosion in the patched material are presented in Figures 18a and 18b for GCL2 and GCL3, respectively. These results illustrate that significant erosion can occur in less than one calendar year.

\section{PRACTICAL IMPLICATIONS}

The dimensions of the larger observed erosion features reported in this paper are such that it is very unlikely the GCL would be able to self-heal upon covering or burial from hydration, swelling and stress effects. For example, Sari and Chai (2013) showed that bentonite-free holes, 40 and $50 \mathrm{~mm}$ in diameter, did not self-heal (after permeation with tap water at a normal stress of $200 \mathrm{kPa}$ ) in a geotextile encased, needle-punched, thermally treated GCL (with a slit-film woven lower geotextile and nonwoven upper geotextile and granular bentonite). As a result, the most significant implication of the observed erosion features would be the loss of the low permeable component of the composite GMB/GCL liner which would negatively impact the potential leakage rates through the composite liner if a hole were to occur at or near the erosion feature.
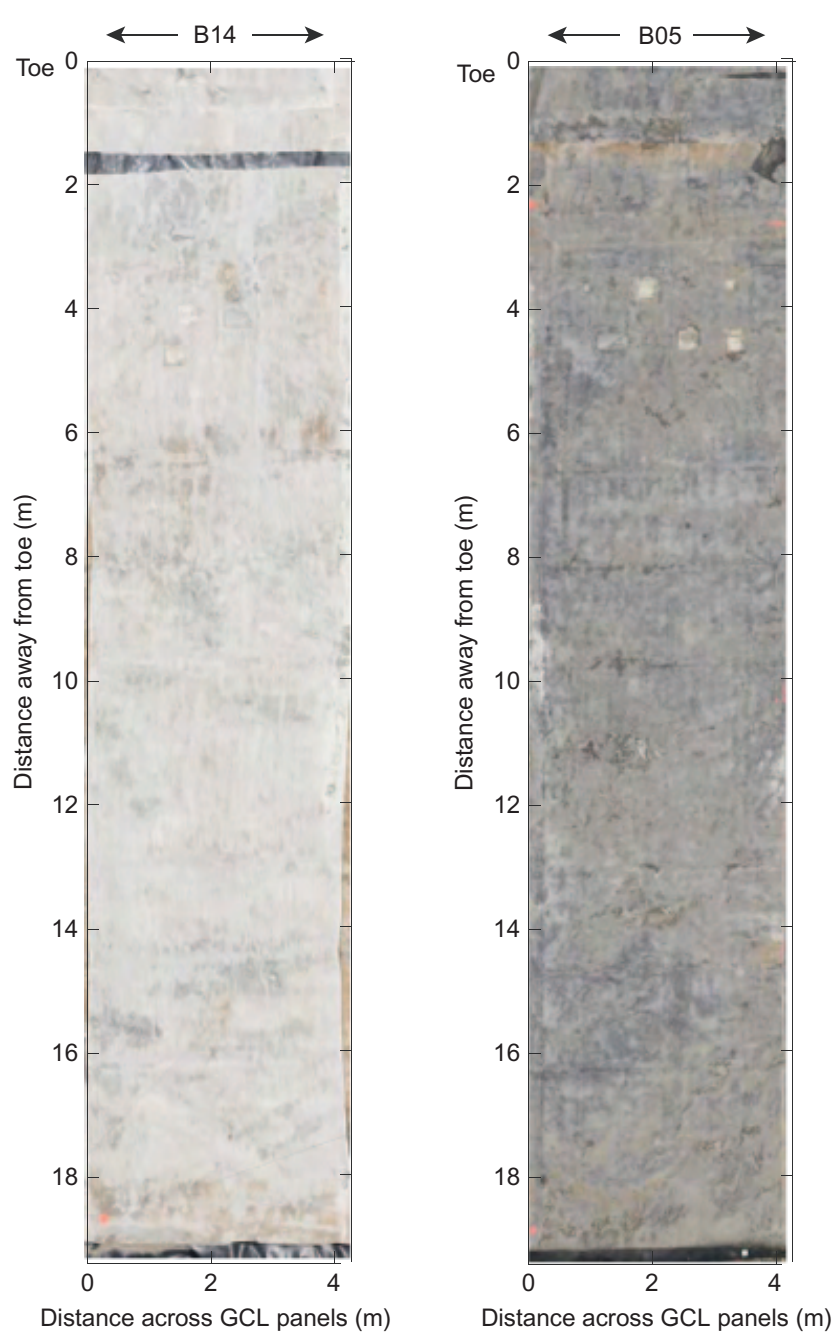

Figure 15. No erosion of bentonite detected in 2011 tactile survey of: (a) GCL1 (panel B14 shown) and (b) GCL3 (panel B05 shown) when products installed on the base with their slit-film woven geotextiles facing up after 4.7 years beneath an exposed smooth black GMB

\section{SUMMARY AND CONCLUSION}

Significant features have been observed for field-exposed geosynthetic clay liners (GCLs) where there was practically no bentonite remaining in the GCL. They were observed at Queen's University Environmental Liner Test Site for four different types of fabric-encased, needlepunched GCLs when installed on top of a silty-sand foundation layer, covered only by a black geomembrane and left exposed (i.e. without the soil cover recommended by GCL manufacturers) for more than 3 years. These features are believed to develop from the cumulative effects of bentonite being transported by small quantities of condensed water vapour flowing along the interface between the geomembrane and GCL, and hence, are called erosion features. When left uncovered, the vapour originates as moisture evaporated from the GCL under solarinduced temperature increases that can then migrate within interconnected spaces between the geomembrane and GCL formed by geomembrane wrinkles.

Erosion features were observed both along a $3 \mathrm{H}: 1 \mathrm{~V}$ $\left(18^{\circ}\right)$ side slope and on a $3 \%\left(2^{\circ}\right)$ sloping base. The 


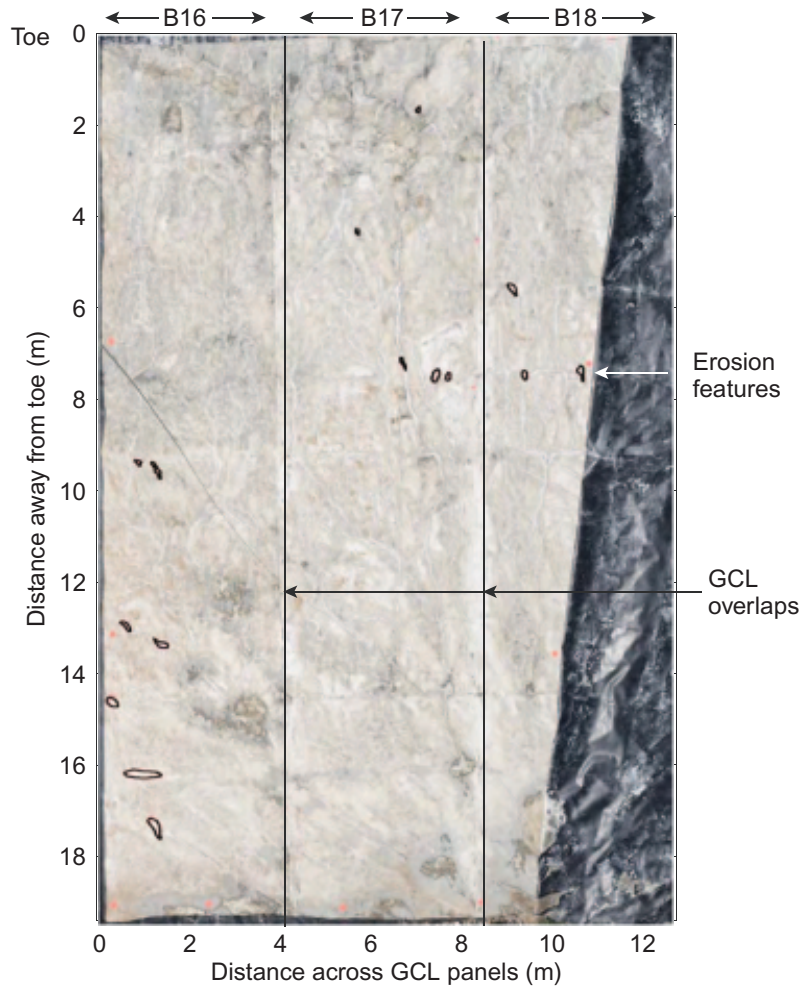

Figure 16. Erosion of bentonite detected in 2011 tactile survey of GCL3 installed nonwoven GTX facing up on the base and covered with a smooth GMB (panels B16-B18) after 4.7 years beneath an exposed black GMB

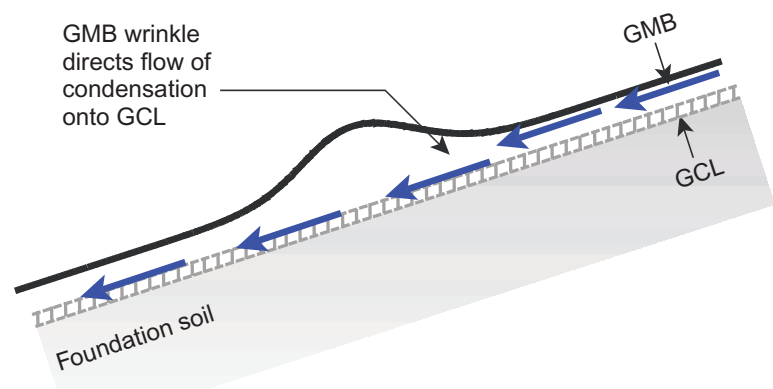

(a)

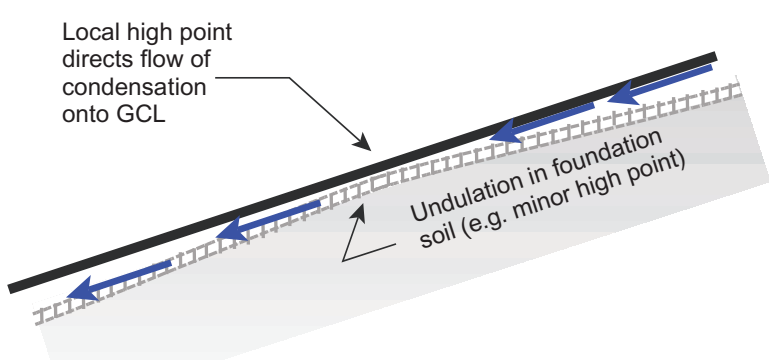

(b)

Figure 17. Condensed water vapour flow concentration mechanisms observed in the field: (a) cross-slope wrinkles, and (b) local high-spots in foundation soil

frequency of features detected on the slope was much higher than on the base. There was no apparent difference in erosion with smooth or textured geomembrane over the same GCL on the side slope. After 4.7 years exposure, the most significant feature detected on the slope was typi- cally $90 \mathrm{~mm}$ wide, had a maximum width of $330 \mathrm{~mm}$ and nearly extended along the entire $21 \mathrm{~m}$ length of the slope; whereas on the base, the most significant feature was up to $50 \mathrm{~mm}$ wide and nearly extended along the entire $19 \mathrm{~m}$ length of the base section. The erosion features observed after 3.6 years of exposure were wide enough (up to $200 \mathrm{~mm}$ wide) that it is very unlikely they can self-heal upon covering or burial from hydration, swelling and stress effects. As a result, the observed erosion features would be expected to adversely impact the hydraulic performance of the GCL and hence negatively impact the potential leakage rates through the composite liner system.

Timely covering of the geomembrane/GCL composite liner with sufficient soil to prevent loss of moisture from the GCL upon hydration would be expected to prevent the development of these erosion features. The nature of the field experiment was such that it is not possible to say when erosion was initiated or became significant; however, partial replacement of two large sections of GCL indicates that significant erosion occurred within 1 year of exposure.

Despite explicit manufacturer recommendations to cover the GCL with $0.3 \mathrm{~m}$ of soil/ballast, it is not uncommon that these liners can be left exposed for periods ranging from several weeks to many months and, in some cases, even longer. For assessment of such cases, it is noted that erosion features were very difficult to find, particularly so for GCLs that had either a black nonwoven geotextile or a slit-film woven geotextile facing up (i.e. towards the geomembrane) and were only detected after exposing entire GCLs panels and carefully conducting tactile inspection of the GCL for bentonite loss. The onset and extent of possible erosion for GCLs covered only by a geomembrane may be expected to depend on many sitespecific factors including: climatic conditions; foundation soil type, water content and preparation; availability of moisture; and inclination and orientation of slope. Consequently, if left uncovered, the onset and extent of erosion features may be less or more extreme than reported here.

\section{ACKNOWLEDGEMENTS}

This research was funded by the Natural Sciences and Engineering Research Council of Canada (NSERC) through a Strategic Project Grant and a Collaborative Research and Development Grant. The investigation of the long-term performance of geosynthetic liner systems was conducted in partnership between Queen's University and Terrafix Geosynthetics Inc., TAG Environmental Inc., Terrafix Environmental Technologies Inc., Solmax International Inc., the Ontario Ministry of the Environment, the Canadian Nuclear Safety Commission, and consulting engineering firms AMEC Earth and Environmental, AECOM and Golder Associates, and the CTT Group. All geosynthetic materials were carefully inspected and independently tested by the authors and were found to be in good condition. The geosynthetics were installed by Terrafix Environmental Inc. in directions that accord with normal industry practice in similar situations. The installation of all geosynthetic materials was monitored and 


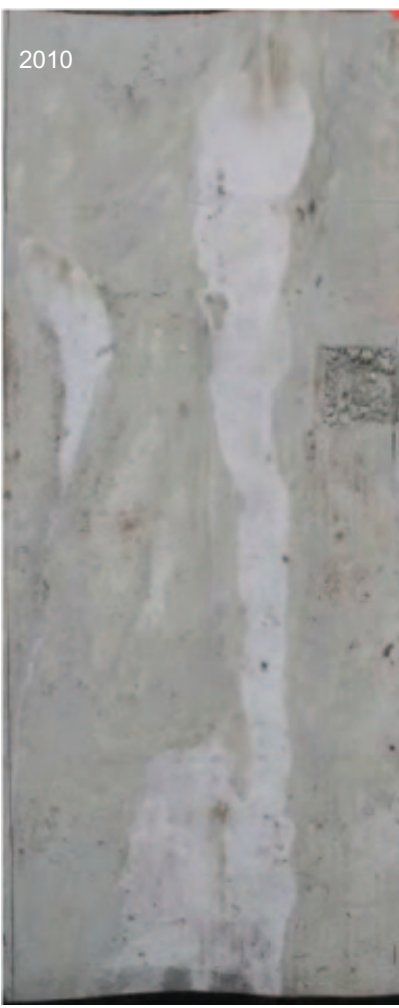

(a)

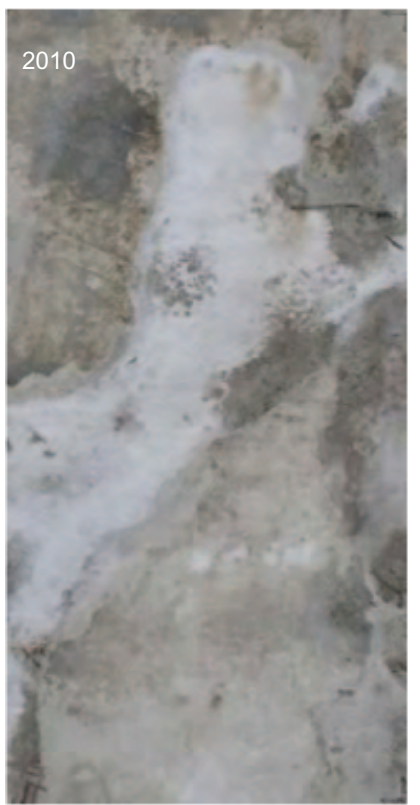

(c)

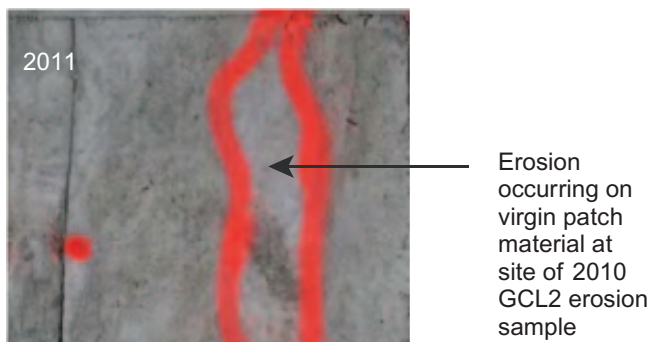

sample (b)

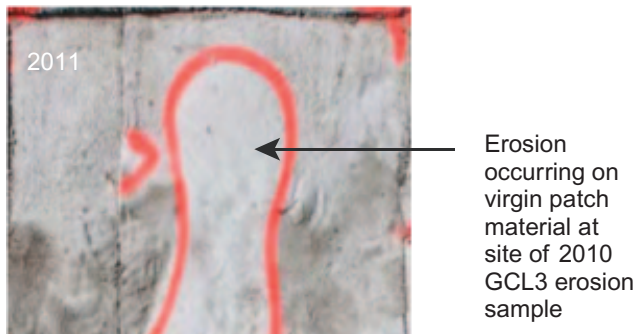

sample

Figure 18. Photographs of erosion sample locations in May 2010 and subsequent erosion of the virgin patch material replacing them as observed in June 2011. These observations illustrate that significant erosion occurred in 1 year for both GCL2 and GCL3

carefully inspected/checked by the authors who were on site throughout construction. The experimental site was constructed on a property owned by Cruickshank Construction Ltd who also conducted the associated earthworks. The use of their property and assistance during construction are greatly appreciated. There was no oversight or role played by any of those acknowledged above, or anyone else other than the authors, in any portion of the study design or in the collection, analysis and interpretation of data, nor in the writing of this paper and the decision to submit it for publication. The authors accept full responsibility for the data and any interpretation or statements made in the paper. The contributions of D.N. Arnepalli with the construction of the field site in 
2006 and A. Rentz with the logistics of the 2011 field inspection are gratefully acknowledged. Additionally, L. Ashe, M. Bentley, D. Brunton, J. Foster, E. Giles, M. Hosney, P. Joshi, C. Mitchell, B. Muller, J. Potvin, E. Watson and R. Wiginton provided very helpful assistance with the field work. The efforts of A. Kerr to obtain the $\mathrm{X}$-ray images in Figures 5 and 6 are very much appreciated.

\section{REFERENCES}

Anderson, R., Rayhani, M. T. \& Rowe, R. K. (2012). Laboratory investigation of GCL hydration from clayey sand subsoil. Geotextiles and Geomembranes, 31, 31-38.

ASTM D 4437 Standard Practice for Non-destructive Testing (NDT) for Determining the Integrity of Seams Used in Joining Flexible Polymeric Sheet Geomembranes. ASTM International, West Conshohocken, PA, USA.

Azad, F., Rowe, R. K., El-Zein, A. \& Airey, D. (2011). Laboratory investigation of thermally induced desiccation of GCLs in double composite liner systems. Geotextiles and Geomembranes, 29, No. 6, $534-543$.

Azad, D., El-Zein, A., Rowe, R. K. \& Airey, D. (2012). Modelling of thermally induced desiccation of geosynthetic clay liners in double composite liner systems. Geotextiles and Geomembranes, 34, 28-38.

Beddoe, R. A., Take, W. A. \& Rowe, R. K. (2010). Development of suction measurement techniques to quantify the water retention curve of GCLs. Geosynthetics International, 17, No. 5, 301-312. [doi: 10.1680/gein.2010.17.5.301].

Beddoe, R. A., Take, W. A. \& Rowe, R. K. (2011). Water retention behaviour of geosynthetic clay liners. ASCE Journal of Geotechnical and Geoenvironmental Engineering, 137, No. 11, 1028-1038.

Benson, C. H., Kucukkirca, I. E. \& Scalia, J. (2010a). Properties of geosynthetics exhumed from a final cover at a solid waste landfill. Geotextiles and Geomembranes, 28, No. 6, 536-546.

Benson, C. H., Ören, A. H. \& Gates, W. P. (2010b). Hydraulic conductivity of two geosynthetic clay liners permeated with a hyperalkaline solution. Geotextiles and Geomembranes, 28, No. 2, 206-218.

Bonaparte, R., Daniel, D. \& Koerner, R. M. (2002). EPA Report, Assessment and recommendations for improving the performance of waste containment systems. Co-operative Agreement Number CR-821448-01-0, USEPA, Washington, DC, USA.

Bostwick, L. E. (2009). Laboratory Study of Geosynthetic Clay Liner Shrinkage when Subjected to Wet/dry Cycles. MSc thesis, Queen's University, Kingston, ON, Canada.

Bostwick, L., Rowe, R. K., Take, W. A. \& Brachman, R. W. I. (2010). Anisotropy and directional shrinkage of geosynthetic clay liners. Geosynthetics International, 17, No. 3, 157-170.

Brachman, R. W. I., Rowe, R. K., Take, W. A., Arnepalli, D. N., Chappel, M., Bostwick, L. E. \& Beddoe, R. A. (2007). Queen's composite geosynthetic liner experimental site. Proceedings of the 61st Canadian Geotechnical Conference, Ottawa, Canada, pp. 2135-2142.

Chappel, M. J., Brachman, R. W. I., Take, W. A. \& Rowe, R. K. (2012). Large-scale quantification of wrinkles in a smooth, black, HDPE geomembrane. ASCE Journal of Geotechnical and Geoenv. Engineering, 137, No. 6, 671-679.

Chevrier, B., Cazaux, D., Didier, G., Gamet, M. \& Guyonnet, D. (2012). Influence of subgrade, temperature and confining pressure on GCL hydration. Geotextiles and Geomembranes, 33, 1-6.

Dickinson, S. \& Brachman, R. W. I. (2006). Deformations of a geosynthetic clay liner beneath a geomembrane wrinkle and coarse gravel. Geotextiles and Geomembranes, 24, No. 5, 285-298.

Dickinson, S. \& Brachman, R. W. I. (2008). Assessment of alternative protection layers for a geomembrane/geosynthetic clay liner (GMGCL) composite liner. Canadian Geotechnical Journal, 45, No. 11, 1594-1610.

Dickinson, S. \& Brachman, R. W. I. (2010). Permeability and internal erosion of a GCL beneath coarse gravel. Geosynthetics International, 17, No. 3, 112-123.
Fox, P. J., DeBattista, D. J. \& Mast, D. G. (2000). Hydraulic performance of geosynthetic clay liners under gravel cover soils. Geotextiles and Geomembranes, 18, No. 2-4, 179-201.

Gates, W. P. \& Bouazza, A. (2010). Bentonite transformations in strongly alkaline solutions. Geotextiles and Geomembranes, 28, No. 2, 219225.

Giroud, J. P. (2005). Quantification of geosynthetic behavior. Geosynthetics International, 12, No. 1, 2-27.

Giroud, J. P. \& Morel, N. (1992). Analysis of geomembrane wrinkles. Geotextiles and Geomembranes, 11, No. 3, 255-276. Erratum: 12, No. 4, 378.

Hornsey, W. P., Scheirs, J., Gates, W. P. \& Bouazza, A. (2010). The impact of mining solutions/liquors on geosynthetics. Geotextiles and Geomembranes, 28, No. 2, 191-198.

Kang, J.-B. \& Shackelford, C. D. (2011). Consolidation enhanced membrane behavior of a geosynthetic clay liner. Geotextiles and Geomembranes, 29, No. 6, 544-555.

Koerner, R. M. \& Narejo, D. (1995). Bearing capacity of hydrated geosynthetic clay liners. ASCE Journal of Geotechnical Engineering, 121, No. 1, 82-85.

Koerner, R. M. \& Koerner, G. R. (2005). In situ separation of GCL panels beneath exposed geomembranes. Geotechnical Fabrics Report, 23, No. 5, 34-39.

Lange, K., Rowe, R. K. \& Jamieson, H. (2010). The potential role of geosynthetic clay liners in mine water treatment systems. Geotextiles and Geomembranes, 28, No. 2, 199-205.

Pelte, T., Pierson, P. \& Gourc, J. P. (1994). Thermal analysis of geomembranes exposed to solar radiation. Geosynthetics International, 1, No. 1, 21-44.

Rayhani, M. T., Rowe, R. K., Brachman, R. W. I., Take, W. A. \& Siemens, G. (2011). Factors affecting GCL hydration under isothermal conditions. Geotextiles and Geomembranes, 29, No. 6, $525-533$.

Rosin-Paumier, S., Touze-Foltz, N., Pantet, A., Monnet, P., Didier, G., Guyonnet, D. \& Norotte, V. (2010). Swell index, oedopermeametric, filter press and rheometric tests for identifying the qualification of bentonites used in GCLs. Geosynthetics International, 17, No. 1, $1-11$.

Rowe, R. K. (2012). Short-and long-term leakage through composite liners. The 7th Arthur Casagrande Lecture. Canadian Geotechnical Journal, 49, No. 2, 141-169.

Rowe, R. K. \& Orsini, C. (2003). Effects of GCL and subgrade type on internal erosion in GCLs under high gradient. Geotextiles and Geomembranes, 21, No. 1, 1-24.

Rowe, R. K. \& Verge, A. (2013). Prediction of geosynthetic clay liner desiccation in low stress applications. Geosynthetics International, 20, No. 5, 301-315.

Rowe, R. K., Quigley, R. M., Brachman, R. W. I. \& Booker, J. R. (2004). Barrier Systems for Waste Disposal Facilities, Taylor \& Francis (Spon), London, UK.

Rowe, R. K., Bostwick, L. E. \& Take, W. A. (2011a). Effect of GCL properties on shrinkage when subjected to wet-dry cycles. ASCE Journal of Geotechnical and Geoenvironmental Engineering, 137, No. 11, 1019-1027.

Rowe, R. K., Rayhani, M. T., Take, W. A., Siemens, G. \& Brachman, R. W. I. (2011b). GCL hydration under simulated daily thermal cycles. Geosynthetics International, 18, No. 4, 196-205.

Rowe, R. K., Chappel, M. J., Brachman, R. W. I. \& Take, W. A. (2012a). Field monitoring of geomembrane wrinkles at a composite liner test site. Canadian Geotechnical Journal, 49, No. 10, 1196-1211.

Rowe, R. K., Yang, P., Chappel, M. J., Brachman, R. W. I. \& Take, W. A. (2012b). Wrinkling of a geomembrane on a compacted clay liner on a slope. Geotechnical Engineering Journal of the SEAGS \& AGSSEA, 43, No. 3, 11-18.

Rowe, R. K., Rayhani, M. T., Take, W. A., Siemens, G. A. \& Brachman, R. W. I. (2013). Physical modelling of nonwoven/nonwoven GCL shrinkage under simulated field conditions. Geotextiles and Geomembranes, 40, 12-19.

Sari, K. \& Chai, J. (2013). Self-healing capacity of geosynthetic clay liners and influencing factors. Geotextiles and Geomembranes, 41, 64-71. 
Shackelford, C. D., Sevick, G. W. \& Eykhol, G. R. (2010). Hydraulic conductivity of geosynthetic clay liners to tailings impoundment solutions. Geotextiles and Geomembranes, 28, No. 2, 149-162.

Siemens, G., Take, W. A., Rowe, R. K. \& Brachman, R. W. I. (2012). Numerical investigation of transient hydration of unsaturated geosynthetic clay liners. Geosynthetics International, 19, No. 3, 232-251.

Stark, T. D., Choi, H. \& Akhtarshad, R. (2004). Occurrence and effect of bentonite migration in geosynthetic clay liners. Geosynthetics International, 11, No. 4, 296-310.

Take, W. A., Chappel, M. J., Brachman, R. W. I. \& Rowe, R. K. (2007). Quantifying geomembrane wrinkles using aerial photography and digital image processing. Geosynthetics International, 14, No. 4, 219-227.

Take, W. A., Rowe, R. K., Munro, H., Kerr, A. \& Schreiner, J. (2009).
Development of X-ray imaging techniques to investigate the internal shrinkage mechanism of GCLs. Geosynthetics '09, Salt Lake City, UT, USA, pp. 19-28.

Take, W. A., Watson, E., Brachman, R. W. I. \& Rowe, R. K. (2012). Thermal expansion and contraction of geomembrane liners subjected to solar exposure and backfilling. ASCE Journal of Geotechnical and Geoenvironmental Engineering, 138, No. 11, 1387-1397.

Take, W. A., Rowe, R. K., Brachman, R. W. I. \& Arenpalli, D. N. (2015). Thermal exposure conditions for a composite liner with a black geomembrane exposed to solar radiation. Geosynthetics International., 22, No. 1, 93-109.

Thiel, R. \& Richardson, G. (2005). Concern for GCL shrinkage when installed on slopes. JGRI-18 at GeoFrontiers, GII Publications, Folsom, PA, USA.

The Editor welcomes discussion on all papers published in Geosynthetics International. Please email your contribution to discussion@geosynthetics-international.com by 15 August 2015. 